\title{
Oxidative Detoxification of Hydrogen Sulphide Detected by Mass Spectrometry in the Soil Amoeba Acanthamoeba castellanii
}

\author{
By DAVID LLOYD, ${ }^{*}+$ BODIL KRISTENSEN AND HANS DEGN \\ Institute of Biochemistry, Odense University, DK-5230 Odense M, Denmark
}

(Received 20 January 1981; revised 25 February 1981)

\begin{abstract}
Respiration of the soil amoeba Acanthamoeba castellanii is stimulated by low concentrations of $\mathrm{H}_{2} \mathrm{~S}$ ( $<17 \mathrm{~Pa}$ in the gas phase); consumption of $\mathrm{H}_{2} \mathrm{~S}$ accompanies respiratory stimulation. Inhibition of the main respiratory chain by $1 \mathrm{mM}-\mathrm{NaN}_{3}$ prevents $\mathrm{H}_{2} \mathrm{~S}$ consumption. At higher concentrations, $\mathrm{H}_{2} \mathrm{~S}$ inhibits respiration incompletely; the inhibition is enhanced by $1 \mathrm{mM}$-salicylhydroxamic acid. Thus this organism has two means of protection against the potentially toxic gas: the ability to oxidize $\mathrm{H}_{2} \mathrm{~S}$, and the presence of alternative pathways of electron transport which are not blocked by this respiratory inhibitor.
\end{abstract}

\section{INTRODUCTION}

The use of inhibitors that bind to the terminal oxidase of the mitochondrial respiratory chain, cytochrome $a+a_{3}$, has provided a key method for the elucidation of electron transport pathways (Degn et al., 1978). Of these inhibitors, $\mathrm{H}_{2} \mathrm{~S}$ is perhaps the most commonly occurring under natural conditions (e.g. in freshwater and marine sediments where $\mathrm{O}_{2}$ concentration is low, and especially in polluted rivers and lakes). Apart from its capacity for ligand binding to haem of cytochrome oxidase (Nicholls, 1975; Nicholls \& Chance, 1974), $\mathrm{H}_{2} \mathrm{~S}$ can also serve as an electron donor at the flavoprotein level of the respiratory chains of some prokaryotes (e.g. the thiobacilli: Trudinger, 1969; Aleem, 1977).

This paper reports that the soil amoeba Acanthamoeba castellanii has at least two mechanisms for protection against the toxic effects of $\mathrm{H}_{2} \mathrm{~S}$. At low concentrations the inhibitor is oxidized; higher concentrations cause only incomplete respiratory inhibition, as the organism has alternative pathways of electron transport (Lloyd et al., 1979).

\section{METHODS}

Abbreviation. SHAM, salicylhydroxamic acid.

Maintenance and growth of organisms. Acanthamoeba castellanii was maintained, grown axenically and counted as described previously (Lloyd et al., 1979).

Simultaneous measurements of $\mathrm{H}_{2} \mathrm{~S}$ and $\mathrm{O}_{2}$ in solution. A quadrupole mass spectrometer fitted with a membrane-covered inlet was used to simultaneously and continuously measure concentrations of $\mathrm{H}_{2} \mathrm{~S}_{\text {and }} \mathrm{O}_{2}$ in an open reaction system (Lundsgaard et al., 1976; Degn et al., 1980). The instrument used was a mass spectrometer type Q8 from VG Micromass (Nat Lane, Winsford, Cheshire CW7 3QH, U.K.) with a turbo-pump type TPH 100 from A. Pfeiffer Vakuumtechnik (D-6334 Asslar 1, F.R.G.).

The cell suspension $(4.5 \mathrm{ml})$ was maintained at $30^{\circ} \mathrm{C}$ in a cylindrical stainless-steel vessel of $7 \mathrm{ml}$ total volume. Stirring was by a cross-shaped stirrer fixed to a stainless-steel shaft entering through a hole in the lid and driven by a synchronous motor. The membrane-covered inlet to the mass spectrometer was sealed into a port lying below the level of the vortex. The membrane $(12 \mu \mathrm{m}$ Teflon) served both to separate the cell suspension from the vacuum and as a gasket between the reaction vessel and mass spectrometer inlet. The response time of the system was limited

$\dagger$ Permanent address: Department of Microbiology, University College, Newport Road, Cardiff CF2 1TA, Wales, U.K. 
by the rate of stirring; the half-time for equilibration with $\mathrm{O}_{2}$ was slightly below 2 min, corresponding to an $\mathrm{O}_{2}$ transfer constant of $7 \times 10^{-3} \mathrm{~s}^{-1}$. Concentration of dissolved $\mathrm{O}_{2}$ (ordinates on Figures) under a constant partial pressure of $\mathrm{O}_{2}$ in the gas phase is linearly and inversely related to steady-state respiration rate.

Inhibitors. Fixed concentrations of $\mathrm{H}_{2} \mathrm{~S}$ in the reaction mixtures were established by allowing $\mathrm{H}_{2} \mathrm{~S} / \mathrm{N}_{2}$ mixtures of known composition to enter the $\mathrm{O}_{2} / \mathrm{N}_{2}$ gas stream to the open reaction vessel (Petersen, 1977). The concentration of $\mathrm{H}_{2} \mathrm{~S}$ in an acetate buffer, $\mathrm{pH} 4 \cdot 5$, in equilibrium with the final gas mixture, was determined by the methylene blue method (Rand et al., 1978). It was found that $\mathrm{H}_{2} \mathrm{~S}$ of $1 \mathrm{mmHg}(133.3 \mathrm{~Pa}$ ) partial pressure in the gas phase is in equilibrium with $0.12 \mathrm{mM}$ undissociated $\mathrm{H}_{2} \mathrm{~S}$ in liquid at $30^{\circ} \mathrm{C} . \mathrm{KCN}$ and $\mathrm{NaN}_{3}$ were used as aqueous solutions ( $\mathrm{pH} 7.4$ ); SHAM was dissolved in ethanol. The percentage inhibition is expressed relative to the respiration rate in the absence of any inhibitor.

\section{RESULTS AND DISCUSSION}

Low concentrations of $\mathrm{H}_{2} \mathrm{~S}$ stimulated the respiration of washed late-exponential phase $A$. castellanii: $17 \mathrm{~Pa} \mathrm{H}_{2} \mathrm{~S}$ in the gas phase gave $38 \%$ stimulation of respiration and the steady-state concentration in the liquid phase remained below a detectable level (Fig. $1 a$ ). Increasing the inhibitor to $25 \mathrm{~Pa}$ resulted in $20 \%$ inhibition of respiration accompanied by a transition to a detectable steady-state level of dissolved $\mathrm{H}_{2} \mathrm{~S}$. When 1 mM-SHAM preceded $\mathrm{H}_{2} \mathrm{~S}$ addition (Fig. $1 b$ ), slight inhibition $(<10 \%)$ of respiration was observed when the gas phase contained $\mathrm{H}_{2} \mathrm{~S}$ in the range 2 to $8 \mathrm{~Pa} ; \mathrm{H}_{2} \mathrm{~S}$ consumption still occurred as shown by the lack of detectable $\mathrm{H}_{2} \mathrm{~S}$ in solution. However, virtually complete inhibition of respiration was observed when $\mathrm{H}_{2} \mathrm{~S}$ was raised to $42 \mathrm{~Pa}$, and free $\mathrm{H}_{2} \mathrm{~S}$ then became detectable in the liquid phase. Exposure of the organisms to this level of $\mathrm{H}_{2} \mathrm{~S}$ caused some irreversible inactivation of the respiratory system, as shown by incomplete recovery on switching from $\mathrm{H}_{2} \mathrm{~S}$ to $\mathrm{N}_{2}$ in the gas stream. Microscopical examination did not reveal any obvious damage to the organisms. Exposure to lower partial pressures of $\mathrm{H}_{2} \mathrm{~S}(<17 \mathrm{~Pa})$ for up to $40 \mathrm{~min}$ gave completely reversible effects.

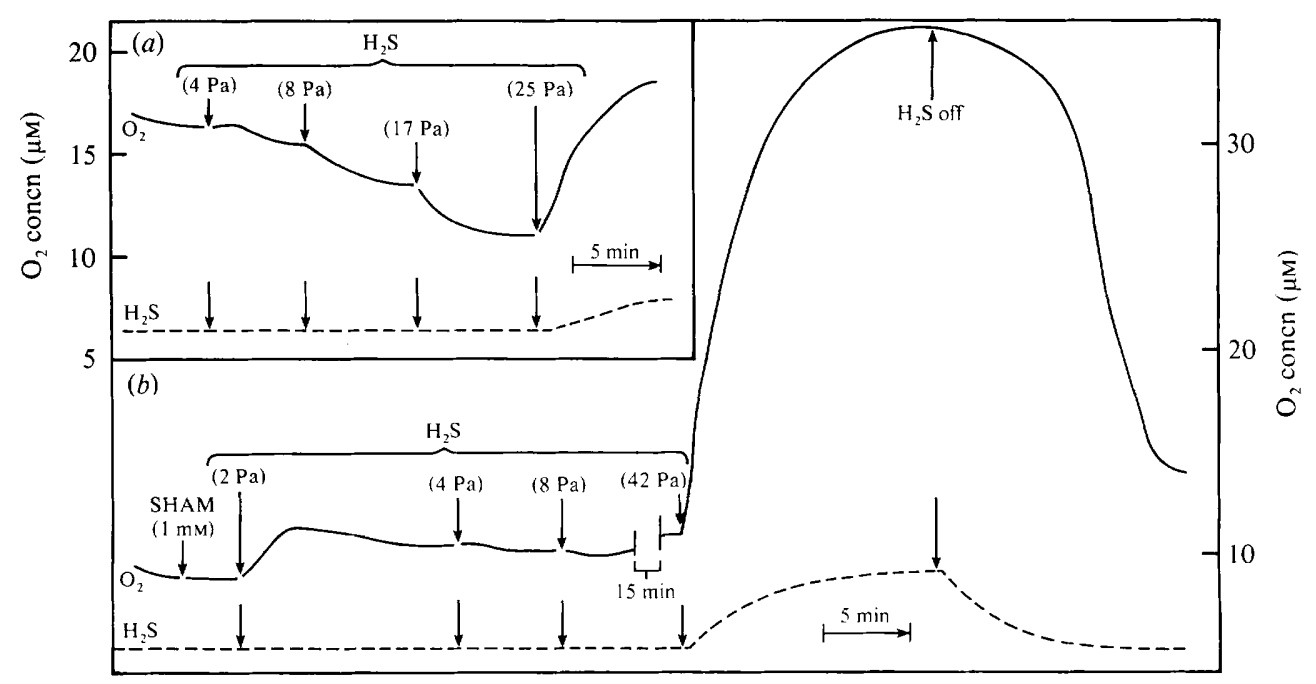

Fig. 1. Effects of $\mathrm{H}_{2} \mathrm{~S}$ on the respiration of a washed suspension of Acanthamoeba castellanii in an open system, measured by mass spectrometry. A late-exponential phase culture $(4.2 \times$ $10^{6}$ organisms $\mathrm{ml}^{-1}$ ) was harvested and the organisms were washed twice and resuspended in $0.9 \%$ $\mathrm{NaCl}$ at a density of $3.4 \times 10^{5}$ organisms $\mathrm{ml}^{-1}$. The gas phase contained $2.5 \% \mathrm{O}_{2}$ in $\mathrm{N}_{2}$ throughout the experiments; $\mathrm{H}_{2} \mathrm{~S}$ was added as indicated into the gas stream entering the open system. - , Dissolved $\mathrm{O}_{2}$ concentration; --- dissolved $\mathrm{H}_{2} \mathrm{~S}$ concentration (arbitrary scale: $\mathrm{H}_{2} \mathrm{~S}$ undetectable at the minimum level shown). 


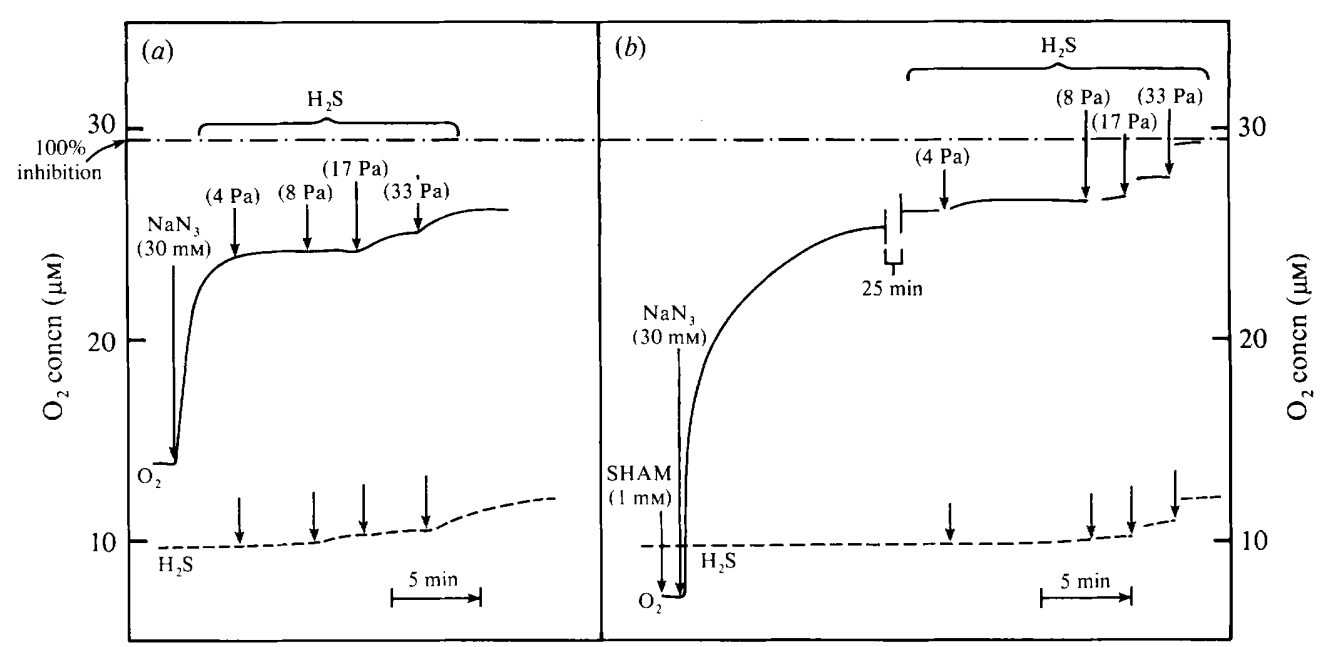

Fig. 2. Effects of $\mathrm{H}_{2} \mathrm{~S}$ on the respiration of a washed suspension of Acanthamoeba castellanii in an open system, measured by mass spectrometry. Conditions were as in Fig. 1, except that the culture was harvested at $4.6 \times 10^{6}$ organisms $\mathrm{ml}^{-1}$ and the cell densities in the experiments were in $(a) 3 \times$ $10^{5}$ organisms $\mathrm{ml}^{-1}$ and in $(b) 6 \times 10^{5}$ organisms $\mathrm{ml}^{-1}$. - , Dissolved $\mathrm{O}_{2}$ concentration; --- , dissolved $\mathrm{H}_{2} \mathrm{~S}$ concentration (arbitrary scale: $\mathrm{H}_{2} \mathrm{~S}$ undetectable at minimum level shown).

When $30 \mathrm{~mm}-\mathrm{NaN}_{3}$ was added to late-exponential phase organisms, almost $70 \%$ inhibition of respiration was observed (Fig. $2 a$ ), and even low partial pressures $\left(<4 \mathrm{~Pa}\right.$ ) of $\mathrm{H}_{2} \mathrm{~S}$ in the gas phase resulted in the accumulation of detectable $\mathrm{H}_{2} \mathrm{~S}$ in solution. Further inhibition of respiration was not observed until the partial pressure of $\mathrm{H}_{2} \mathrm{~S}$ was increased to $17 \mathrm{~Pa}$. When $1 \mathrm{mM}-\mathrm{SHAM}$ was added and then $30 \mathrm{mM}-\mathrm{NaN}_{3}$, eventually $85 \%$ of the respiratory activity was inhibited (Fig. $2 b$ ). Increasing the partial pressure of $\mathrm{H}_{2} \mathrm{~S}$ from 4 to $33 \mathrm{~Pa}$ then gave complete inhibition whilst accumulating in solution. Similar results were obtained when $1 \mathrm{mM}-\mathrm{NaN}_{3}$ replaced $30 \mathrm{~mm}-\mathrm{NaN}_{3}$. Addition of $1 \mathrm{~mm}-\mathrm{SHAM}$ or $1 \mathrm{~mm}-\mathrm{NaN}_{3}$ after adjusting the partial pressure of $\mathrm{H}_{2} \mathrm{~S}$ to $42 \mathrm{~Pa}$ gave further inhibition of respiration. These results were typical of twelve experiments with five different batches of organisms. Similar observations were also made in nine further experiments with three separate batches of cells harvested in the early-exponential growth phase. In all cases respiratory stimulation was accompanied by $\mathrm{H}_{2} \mathrm{~S}$ consumption, and conditions which inhibited respiration via the main respiratory chain always led to the accumulation of $\mathrm{H}_{2} \mathrm{~S}$ in solution. The residual respiration observed in the presence of $30 \mathrm{mM}-\mathrm{NaN}_{3}, 1 \mathrm{mM}-\mathrm{SHAM}$ and $33 \mathrm{~Pa} \mathrm{H}_{2} \mathrm{~S}$ was not inhibited by $2 \mathrm{mM}-\mathrm{KCN}$.

Thus this soil amoeba can dispose of $\mathrm{H}_{2} \mathrm{~S}$ when this potentially toxic agent is encountered at low concentrations. At higher concentrations it can survive extended exposure times by using electron transport pathways alternative to the main respiratory chain. The former mechanism has not previously been reported for any eukaryote; oxidation of $\mathrm{H}_{2} \mathrm{~S}$ has been regarded as a prokaryotic prerogative. The latter mechanism provides a clear function for the simultaneous operation of alternative electron transport chains.

\section{REFERENCES}

AlEem, M. I. H. (1977). Coupling of energy with electron transfer reactions in chemolithotrophic bacteria. Symposia of the Society for General Microbiology 27, 351-381.

Degn, H., Lloyd, D. \& Hill, G. C. (1978). Functions of Alternative Terminal Oxidases. Oxford: Pergamon Press.
Degn, H., Lundsgaard, J. S., Petersen, L. C. \& ORMicki, A. (1980). Polarographic measurement of steady state kinetics of oxygen uptake by biochemical samples. Methods of Biochemical Analysis 26, 47-77.

Lloyd, D., Edwards, S. W., KRISTENSEN, B. \& DEGN, H. (1979). The effects of inhibitors on the 
oxygen kinetics of terminal oxidases of Acanthamoeba castellanii. Biochemical Journal 182, $11-15$.

Lundsgaard, J. S., Petersen, L. C. \& Degn, H. (1976). Mass spectrometric determination of oxygen kinetics in biochemical systems. In Measurements of Oxygen, pp. 168-183. Edited by H. Degn, I. Balsley \& R. Brook. Amsterdam: Elsevier.

Nicholls, P. (1975). The effect of sulphide on cytochrome $a a_{3}$ : isosteric and allosteric shifts of the reduced alpha-peak. Biochimica et biophysica acta 396, 24-35.

Nicholls, P. \& Chance, B. (1974). Cytochrome oxidase. In Molecular Mechanisms of Oxygen
Activation, pp. 479-534. Edited by O. Hayaishi. New York: Academic Press.

Petersen, L. C. (1977). The effect of inhibitors on the oxygen kinetics of cytochrome $c$ oxidase. Biochimica et biophysica acta 460, 299-307.

Rand, M. C., Greenberg, A. E. \& Taras, M. J. (1978). Standard Methods for the Examination of Water and Waste Water, 14th edn, pp. 503-565. Washington: American Public Health Association.

Trudinger, P. A. (1969). Assimilatory and dissimilatory metabolism of inorganic sulphur compounds by microorganisms. Advances in Microbial Physiology 3, 111-158. 